\title{
Distrito Federal
}

National Cancer Institute

\section{Source}

National Cancer Institute. Distrito Federal. NCI Thesaurus. Code C156319.

A state in the Central-West Region of Brazil. It contains the Brazilian capital city, Brasilia. 